\title{
Diabetes promotes invasive pancreatic cancer by increasing systemic and tumour carbonyl stress in $\mathrm{Kras}^{\mathrm{G} 2 \mathrm{D} /+}$ mice
}

Stefano Menini ${ }^{1+}$, Carla lacobini ${ }^{1+}$, Luisa de Latouliere ${ }^{1,2}$, Isabella Manni ${ }^{2}$, Martina Vitale ${ }^{1}$, Emanuela Pilozzi ${ }^{1,3}$, Carlo Pesce ${ }^{4}$, Paola Cappello ${ }^{5}$, Francesco Novelli ${ }^{5}$, Giulia Piaggio ${ }^{2}$ and Giuseppe Pugliese $e^{1 *}$ (D)

\begin{abstract}
Background: Type 1 and 2 diabetes confer an increased risk of pancreatic cancer $(\mathrm{PaC})$ of similar magnitude, suggesting a common mechanism. The recent finding that $\mathrm{PaC}$ incidence increases linearly with increasing fasting glucose levels supports a central role for hyperglycaemia, which is known to cause carbonyl stress and advanced glycation end-product (AGE) accumulation through increased glycolytic activity and non-enzymatic reactions. This study investigated the impact of hyperglycaemia on invasive tumour development and the underlying mechanisms involved.
\end{abstract}

Methods: $P d \times 1-C r e ; L S L-K r a s^{G 12 D /+}$ mice were interbred with mitosis luciferase reporter mice, rendered diabetic with streptozotocin and treated or not with carnosinol (FL-926-16), a selective scavenger of reactive carbonyl species (RCS) and, as such, an inhibitor of AGE formation. Mice were monitored for tumour development by in vivo bioluminescence imaging. At the end of the study, pancreatic tissue was collected for histology/ immunohistochemistry and molecular analyses. Mechanistic studies were performed in pancreatic ductal adenocarcinoma cell lines challenged with high glucose, glycolysis- and glycoxidation-derived RCS, their protein adducts AGEs and sera from diabetic patients.

Results: Cumulative incidence of invasive PaC at 22 weeks of age was $75 \%$ in untreated diabetic vs $25 \%$ in FL-92616-gtreated diabetic and 8.3\% in non-diabetic mice. FL-926-16 treatment suppressed systemic and pancreatic carbonyl stress, extracellular signal-regulated kinases (ERK) 1/2 activation, and nuclear translocation of Yes-associated protein (YAP) in pancreas. In vitro, RCS scavenging and AGE elimination completely inhibited cell proliferation stimulated by high glucose, and YAP proved essential in mediating the effects of both glucose-derived RCS and their protein adducts AGEs. However, RCS and AGEs induced YAP activity through distinct pathways, causing reduction of Large Tumour Suppressor Kinase 1 and activation of the Epidermal Growth Factor Receptor/ERK signalling pathway, respectively.

(Continued on next page)

\footnotetext{
* Correspondence: giuseppe.pugliese@uniroma1.it

${ }^{+}$Stefano Menini and Carla lacobini contributed equally to this work.

'Department of Clinical and Molecular Medicine, "La Sapienza" University, Via di Grottarossa, 1035-1039 -, 00189 Rome, Italy

Full list of author information is available at the end of the article
} 


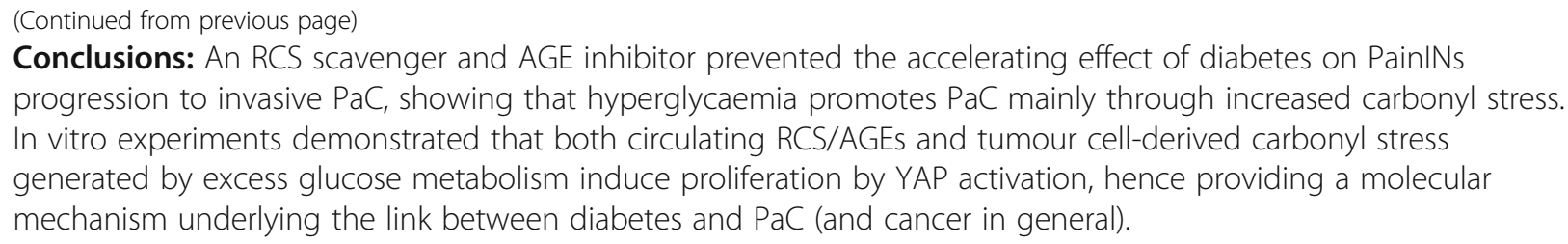

Keywords: Pancreatic ductal adenocarcinoma, Hyperglycaemia, Reactive carbonyl species, Methylglyoxal, Advanced glycation end-products, Carnosine derivatives, Yes-associated protein, Large tumour suppressor kinase 1, Epidermal growth factor receptor, Extracellular signal-regulated kinases 1/2

\section{Background}

Pancreatic cancer $(\mathrm{PaC})$ is the tenth most common incident cancer, but the seventh leading cause of cancerrelated death worldwide [1], because of the poor 5-year survival outcomes [2]. Due to the rising prevalence of risk factors such as obesity and type 2 diabetes, $\mathrm{PaC}$ is expected to become the second leading cause of cancerrelated death in the US by 2030 [3]. Type 2 diabetes was found to be associated with a 5-7-fold higher risk of $\mathrm{PaC}$ in the first year after diabetes diagnosis and nearly twofold thereafter $[4,5]$. Though type 2 diabetes is the main contributor to this problem, the entity and temporal trajectory of $\mathrm{PaC}$ risk were recently reported to be similar in type 1 diabetes [6], suggesting a common mechanism related to hyperglycaemia. This concept is supported by the recent finding that $\mathrm{PaC}$ incidence increases linearly with increasing fasting glucose levels, even within the normal range [7].

Previous studies have shown that type 2 diabetes induced by a high-fat diet promotes $\mathrm{PaC}[8,9]$. However, this experimental model of the metabolic syndrome does not allow assessing the role of hyperglycaemia independent of confounding factors such as obesity and hyperinsulinemia, thus hindering the understanding of the mechanisms underlying the risk conferred by hyperglycaemia. We have recently demonstrated that advanced glycation end-products (AGEs) promote proliferation of human pancreatic ductal adenocarcinoma (PDA) cell lines and that exogenous AGE administration markedly accelerates invasive tumour development in a mouse model of Kras-driven $\mathrm{PaC}$ [10]. Accumulation of AGEs in diabetes is mainly due to increased formation of reactive carbonyl species (RCS) derived from glucose auto-oxidation (e.g. glyoxal, GO), but also from cell metabolism of excess glucose through glycolysis (e.g., methylglyoxal, MGO) [11]. In turn, RCS react with amino groups of proteins causing structural and functional modifications. The resulting irreversible adducts (i.e., AGEs) accumulate in tissues, where they can exert further biological effects through interaction with specific receptors $[12,13]$.

Carnosine (beta-alanyl-L-histidine) is an endogenous histidine-containing dipeptide that inhibits AGE formation by scavenging RCS [14]. Though L-Carnosine was proven to be effective in several carbonyl stressrelated disease conditions [15], including metabolic disorders [16-19], its therapeutic use in humans is hampered by the presence of high levels of serum carnosinase, thus prompting the search for carnosinaseresistant carnosine derivatives [18-20]. The novel bioavailable compound carnosinol, i.e., (2S)-2-(3-amino propanoylamino)-3-(1H-imidazol-5-yl) propanol (FL926-16) [18-22], was shown to be highly effective in attenuating diabetes-associated vascular complications [21, $22]$ and obesity-related metabolic dysfunctions $[18,19]$. Moreover, it was recently shown that L-carnosine is effective in counteracting glycolysis-dependent tumour growth by quenching RCS [23].

This study aimed at investigating whether hyperglycaemia associated with experimental type 1 diabetes favours the progression of preneoplastic lesions to malignancy in a well-validated mouse model of $\mathrm{PaC}$ by increasing carbonyl stress. To this end, mice were treated with the RCS scavenger and inhibitor of AGE formation FL-926-16. An additional objective was to analyse the effect of the diabetic milieu and of FL-92616 on the activity of Yes-associated protein (YAP), a key downstream target of KRAS signalling required for progression of pancreatic intraepithelial neoplasias (PanINs) to invasive $\mathrm{PaC}[24,25]$ and for MGO-induced tumour growth [23].

\section{Methods}

\section{In vivo study}

The experimental protocols comply with the principles of (https://www.nc3rs.org.uk/arrive-guidelines) and were approved by the National Ethics Committee for Animal Experimentation of the Italian Ministry of Health (Authorization no. 1470/2015-PR). The mice were housed in single cages with wood-derived bedding material in a specific pathogen-free facility with a 12-h light/dark cycle under controlled temperatures $\left(20-22^{\circ} \mathrm{C}\right)$. Mice were cared for in accordance with the Principles of Laboratory Animal Care (National Institutes of Health publ. no. 8523, revised 1985) and with national laws, and received 
water and food ad libitum. The primary and secondary endpoint were the development of invasive $\mathrm{PaC}$ and the development/progression of PanINs, respectively.

\section{Design}

The effect of diabetes on $\mathrm{PaC}$ progression was investigated in Pdx1-Cre;LSL-Kras ${ }^{G 12 D /+}$ (KC) mice, which develop autochthonous $\mathrm{PaC}$ in a pattern recapitulating human pathology with high fidelity by developing the full spectrum of $\mathrm{PaC}$ progression, from preneoplastic lesions (PanINs) to adenocarcinoma and metastasis $[26,27]$. $\mathrm{KC}$ mice were interbred with mitosis luciferase $(M I T O-L u c)$ reporter mice to obtain KC-Mito (KCM) mice $[10,28,29]$. The $L S L$ $\mathrm{Kras}^{\mathrm{G} 12 \mathrm{D} /+}$ lineage was maintained in the heterozygous state. Mice were screened by polymerase chain reaction (PCR) using tail DNA amplified by specific primers to the Lox-P cassette flanking mutated $\mathrm{Kras}^{\mathrm{G12D/+}}$, wild type Kras,
Cre recombinase and MITO genes, as previously reported [10, 29]. In the MITO-Luc mouse, an artificial minimal promoter derived from the cyclin B2 gene and induced by NF$\mathrm{Y}$ drives the expression of the luciferase reporter specifically in replicating cells. Therefore, both normal (e.g., bone marrow) and tumour actively proliferating cells may be localized by a bioluminescence imaging (BLI)-based screen [10, 28, 29]. We have previously shown that KCM mice develop pre-invasive (PanINs) and invasive ductal $\mathrm{PaC}$ with the same penetrance, latency, and histological features as those described for $\mathrm{KC}$ mice [29]. According to the Ethics Committee recommendations, to limit the number of animals, the experiments were stopped when it was sufficient to confirm or reject the working hypothesis in a statistically and clinically meaningful manner.

Figure 1 shows the flowchart and timeline of study design. Thirty-three KCM mice were rendered diabetic
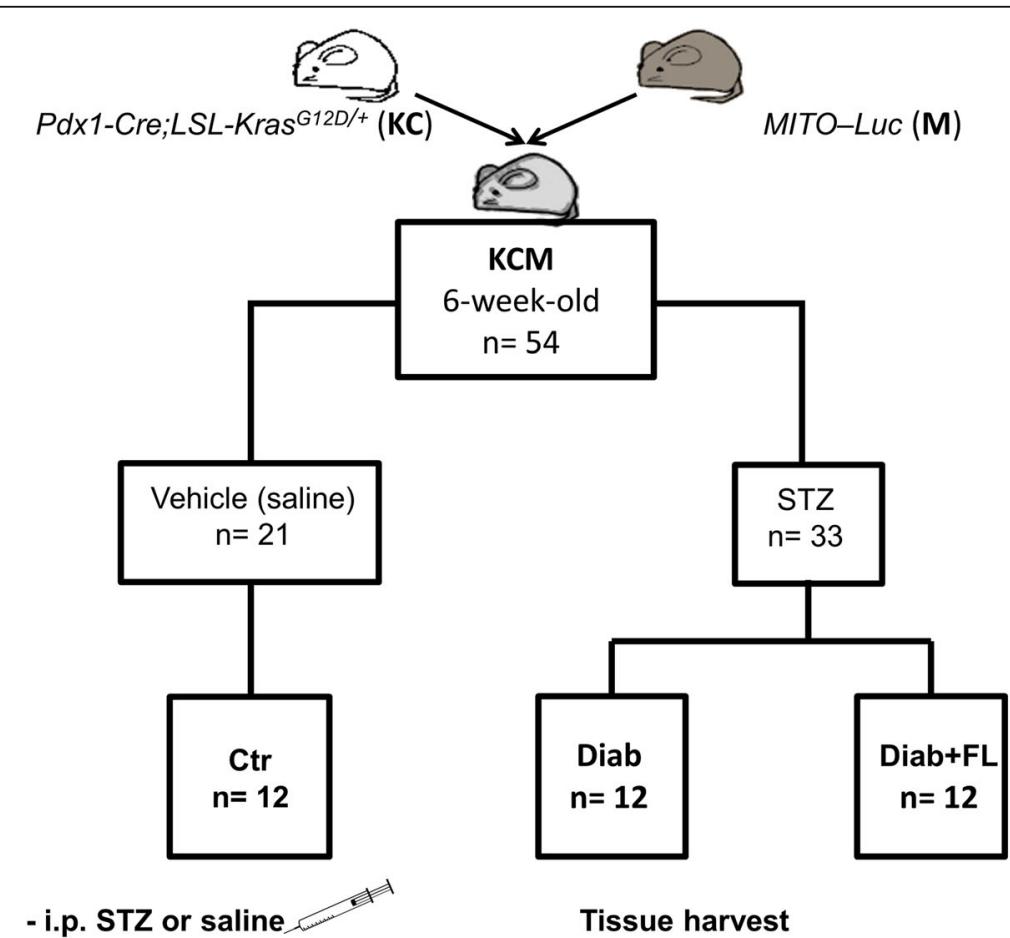

- FL-926-16 (3 days post injection)

Tissue harvest

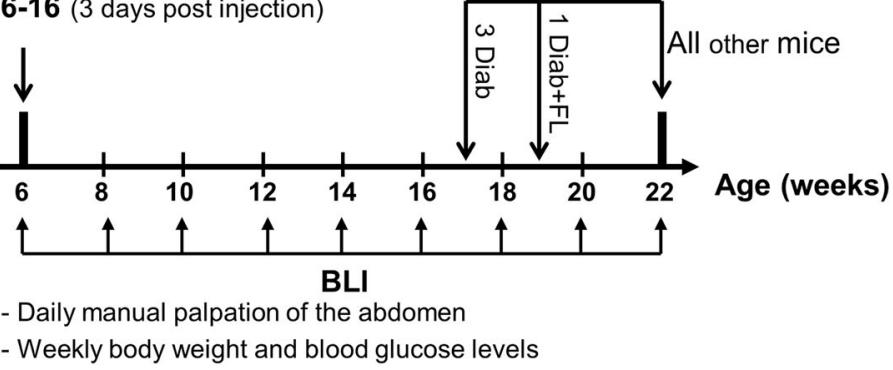

Fig. 1 Flowchart and timeline of study design. Please refer to the text for detailed description. In dashed boxes, groups of non-diabetic KCM mice (Ctr) that served as control for the effect of STZ (STZ-non-Diab) or FL-926-16 (FL) treatment ( $\mathrm{Ctr}+\mathrm{FL}$ ) on PaC development and progression. To avoid unnecessary suffering, three diabetic mice (Diab) and one Diab mouse treated with FL (Diab+FL) were killed 5 and 3 weeks, respectively, before the end of the study. STZ = streptozotrocin; BLI = bioluminescence imaging 
with streptozotocin (STZ) and followed for 16 weeks (i.e., up to 22 weeks of age). After an overnight fast, 6week-old mice were intraperitoneally injected with 190 $\mathrm{mg} \cdot \mathrm{kg}^{-1}$ STZ (Sigma-Aldrich, St. Louis, MO, USA). Success rate, defined as the percentage of STZ-injected mice with glucose levels $>250 \mathrm{mg} / \mathrm{dL}$ for the entire study period was $72.7 \%$ (24/33). Three days after injection, diabetic mice were randomized to receive no treatment (Diab, $n=12$ ) or FL-926-16 (gift of Flamma S.p.A., Chignolo d'Isola, Italy) [30] at a dose of $30 \mathrm{mg} \cdot \mathrm{kg}^{-1}$. day $^{-1}$ in the drinking water $(D i a b+F L, n=12)$ and injected weekly with $1 \mathrm{IU}$ of insulin glargine to prevent excessive weight loss and ketoacidosis. FL-926-16 was shown to have a suitable absorption, distribution, metabolism, excretion, and toxicity (ADMET) profile, and the greatest potency and selectivity toward RCS among all other carnosine derivatives [18]. The FL-926-16 dose was chosen based on previous results from our group [22], showing high efficacy in preventing diabetesinduced renal injury, and from other investigators, indicating a good safety profile at the dose of $10-45 \mathrm{~g} \cdot \mathrm{kg}^{-1}$. day $^{-1}[18,30]$. Neither histological abnormalities of the liver, kidney, lung, and heart, nor functional abnormalities attributable to toxicity on these tissues were observed in this study or in a previous one [22]. STZtreated mice not fulfilling the criteria for diabetes diagnosis (STZ-non-Diab, $n=9$ ) served as control for STZ effect on $\mathrm{PaC}$; seven of these mice failed to develop hyperglycaemia, whereas two had spontaneous recovery from diabetes within 2 weeks. Vehicle (saline)-injected KCM mice were used as non-diabetic controls and either left untreated (Ctr; $n=12$ ) or treated with FL-926$16(\mathrm{Ctr}+\mathrm{FL} ; \mathrm{n}=9)$ to check for any drug effect.

Mice were subjected to in vivo BLI every other week $[10,29]$ and daily manual palpation of the abdomen to check for tumour growth and avoid the loss of animals, along with the need to cope with the related ethical issues (i.e., compliance with the 3Rs principles). Briefly, $10 \mathrm{~min}$ after administration of Dluciferin $(75 \mathrm{mg} / \mathrm{kg}$ body weight, intraperitoneal; Perkin Elmer, Hopkinton, MA, USA), photon emission from the different body areas was acquired for $5 \mathrm{~min}$ and analysed with a CCD camera (Xenogen IVIS Lumina System; Perkin Elmer). A specific region of interest (ROI) corresponding to the abdominal area occupied by the pancreas was manually selected and the total photon flux $(\mathrm{p} / \mathrm{s})$ from this ROI was evaluated with Living Image software (Caliper Life Sciences; Perkin Elmer) [10, 28, 29].

At the end of the study, mice were anaesthetized with ketamine $\left(60 \mathrm{mg} \cdot \mathrm{kg}^{-1}\right.$ Imalgene i.p.) and xylazine (7.5 mg.kg- ${ }^{-1}$ Rompum i.p.) and killed by cervical dislocation. According to the Ethics Committee recommendations, to avoid suffering, three Diab and one Diab+FL mice presenting with both positive BLI and a palpable abdominal mass or poor general condition were killed 5 and 3 weeks, respectively, before the end of the study. The lungs and the middle part of the gastrointestinal tract, including the pancreas and the liver, were dissected, and exposed to the CCD camera for $5 \mathrm{~min}$ for photon emission assessment. The pancreas was dissected, photographed and weighted; then one part was stored at $-80^{\circ} \mathrm{C}$ for molecular analysis, whereas the other part was processed for histological/immunohistochemical analysis [10]. At time of collection, a technician (C.C., see Acknowledgements) recoded biological samples to allow blinded analysis.

\section{Metabolic parameters}

Body weight and blood glucose were monitored weekly. At the end of the study, the levels of haemoglobin $(\mathrm{Hb})$ A1c, an indicator of long-term glycaemic control, were assessed by using the Mouse HbA1c Assay Kit (80,310, Crystal Chem, Zaandam, Netherlands), and serum AGEs and total protein carbonyls (PCOs), two carbonyl stress markers, were measured by ELISA (OxiSelect ${ }^{\mathrm{tm}}$ Advanced Glycation End-Product Competitive ELISA Kit, no. STA-817 and OxiSelect ${ }^{\text {tw }}$ Protein Carbonyl ELISA Kit, no. STA-310, respectively, Cell Biolabs, Inc., San Diego, CA, USA).

\section{Pancreas histology}

Six $4-\mu$ m-thick non-serial pancreatic sections stained with haematoxylin and eosin were examined to confirm the presence of invasive $\mathrm{PaC}$. Pancreas without invasive $\mathrm{PaC}$ were analysed to grade dysplastic ducts (i.e., PanINs) according to previously established criteria [26]. The numbers of low-grade (PanIN-1A/B) and high-grade (PanIN-2/3) dysplastic ducts were counted and expressed as a percentage of total ducts in the specimen [10].

\section{Pancreatic AGEs}

ERK 1/2 phosphrylation status, nuclear YAP, and its target gene connective tissue growth factor (CTGF). Levels of AGEs, p-ERK 1/2, and CTGF protein in homogenates and of active (non-phosphorylated) YAP1 in nuclear extracts of pancreas of mice were assessed by Western blot. Human PDA tissues $(n=14)$ were obtained from the Pathology Unit of Sant'Andrea Hospital, Rome, Italy, in agreement with the ethical guidelines established by the locally appointed Ethics Committee. Pancreatic tissue distribution of AGEs and activated YAP1 in mouse and human specimens were evaluated by dual label immunofluorescence and immunoperoxidase, respectively [10, 31]. For immunofluorescence, a goat polyclonal anti-AGE antibody and a rabbit 
monoclonal antibody to active (non-phosphorylated) YAP1 were used as primary antibodies, followed by appropriate secondary fluorescent antibodies (see Supplementary Table S1 for antibodies in Additional file 1). Sections were analysed at a fluorescence microscope (Zeiss AXIO A1), equipped with an Axiocam 503 color camera (Carl Zeiss Italy, Milan, Italy). For immunoperoxidase, formalin-fixed paraffin embedded sections (4$\mu \mathrm{m}$ thick) were rehydrated and treated with $0.3 \% \mathrm{H}_{2} \mathrm{O}_{2}$ in PBS for 30 min to block endogenous peroxidase activity. Heat mediated antigen retrieval was performed with "Antigen Unmasking Solution, Citric Acid Based" (H3300, Vector Laboratories, Burlingame, CA, USA) for AGE staining, or Tris/EDTA buffer $\mathrm{pH} 9.0$, for YAP staining, both for $20 \mathrm{~min}$. Nonspecific binding was blocked by incubation in Protein block serum free (Agilent/Dako, Santa Clara, CA, USA) for $30 \mathrm{~min}$ at room temperature. Then, sections were incubated with Avidin/Biotin blocking Kit (SP-2002, Vector Laboratories) for $30 \mathrm{~min}$, an anti-AGE antibody (Abcam, Cambridge, UK, ab23722) or an antibody directed to the active (non-phosphorylated) YAP1 (Abcam, ab205270) at $4{ }^{\circ} \mathrm{C}$ overnight, and the appropriate biotinylated secondary antibody at room temperature for $30 \mathrm{~min}$ (see Supplementary Table S1 for antibodies in Additional file 1). Finally, sections were stained with UltraTek Horseradish Peroxidase (ABL015, ScyTek Laboratories, UT, USA) for $10 \mathrm{~min}$ followed by 3,3-diaminobenzidine (DAB) $/ \mathrm{H}_{2} \mathrm{O}_{2}$ Chromogen/Substrate Kit (High Contrast) (ACV500, ScyTek Laboratories) until the reaction product was visualized $(\sim 3 \mathrm{~min})$, and counterstained with hematoxylin. AGE positive staining and nuclear expression of YAP were measured in 10 random fields of each section at a final magnification of $250 \mathrm{X}$ and $400 \mathrm{X}$, respectively, by means of the interactive image analyzer Image-Pro Premier 9.2 (Immagini\&Computer, Milan, Italy). AGE positivity was expressed as the mean percentage of field's area occupied by the specific stain. Expression status of active YAP in tumor specimens was assessed by counting the number of nuclei positive for YAP and expressed as the mean ratio (\%) of YAPpositive nuclei to total nuclei.

\section{In vitro study}

The in vitro study investigated the putative role of RCS and AGEs as mediators of the tumourpromoting effect of high glucose (HG) and the protective effect of the carbonyl-sequestering agent and AGE inhibitor FL-926-16.

\section{Design}

Human MIA PaCa-2 (Catalogue No. 85062806, Lot No. 14A02) and Panc-1 (Catalogue No. 87092802, Lot No. 10G011) cells (Sigma-Aldrich) were used for assessing the effects of HG and FL-926-16 on cell proliferation. Experiments aimed at investigating the molecular mechanisms underlying the glucose-mediated effects and the protection by FL-926-16 were conducted on MIA PaCa-2 cells. Mycoplasma contamination in cell cultures was regularly tested by PCR MycoSPY Kit (Biontex Laboratories GmbH, Munchen, Germany). Human PDA cells were maintained in DMEM supplemented with 10\% FBS and incubated in different conditions for three days, i.e., (1) normoglycaemia (normal glucose, $5 \mathrm{mM}$ ); (2) hyperglycaemia (HG, $25 \mathrm{mM}$ ); treated with (3) MGO or GO $(200 \mu \mathrm{M}$, SigmaAldrich), two RCS and AGE precursors, or (4) the preformed AGE $\mathrm{N}^{\varepsilon}$-carboxymethyllysine (CML, $100 \mu \mathrm{g} / \mathrm{mL}$ ), prepared as previously reported $[10,21]$, with or without FL-926-16 (20 mM); and (5) exposed to DMEM low glucose medium containing $10 \%$ of pooled sera from nondiabetic or diabetic individuals, before and after AGE removal from diabetic serum by an immunoadsorption method (see below), with or without FL-926-16 (20 mM). Informed consent was obtained from non-diabetic and diabetic individuals. Moreover, both YAP and Epidermal Growth Factor Receptor (EGFR) were silenced to assess the role of YAP and EGFR pathway in RCS and AGEinduced cell proliferation (see below).

\section{Removal of AGEs from diabetic serum}

AGEs were removed from diabetic serum using an immunoadsorption method. To immunoprecipitate AGE-modified proteins, $500 \mu \mathrm{l}$ of diabetic serum was incubated for $1 \mathrm{~h}$ with $25 \mu \mathrm{l}$ of Pierce NHS-activated magnetic beads (Thermofisher Scientific) covalently conjugated with $10 \mu \mathrm{g}$ of anti-AGE antibody (Abcam, see Supplementary Table S1 for antibodies in Additional file 1), according to the manufacturer instruction. To confirm the efficiency of AGE depletion, AGE concentration in both treated (unbound serum fraction) and untreated diabetic serum was evaluated in triplicate by ELISA (OxiSelect ${ }^{\text {TM }}$ Advanced Glycation End-Product Competitive ELISA Kit, no. STA-817, Cell Biolabs, Inc., San Diego, CA, USA). Following this procedure, the concentration of AGEs in diabetic serum was reduced by about $60 \%$, reaching a concentration similar to that of the non-diabetic serum (see the "Results" section).

\section{YAP and EGFR silencing}

YAP and EGFR were silenced using small interfering RNAs (siRNAs) and irrelevant scrambled siRNAs as control (Thermo Fisher Scientific, Waltham, MA, USA). Validated predesigned siRNA oligonucleotides and related TaqMan assays are detailed in Supplementary Table S2 (see Additional file 1). Lipofectamine RNAiMAX (Thermo Fisher Scientific) transfections were performed using $20 \mathrm{nM}$ of each siRNA. 


\section{Cell survival and proliferation}

Cell viability and proliferation were evaluated by Cytoselect WST-1 Cell Proliferation Assay (Cell Biolabs) following the manufacturer instructions.

$Y A P 1$, its upstream regulators large tumour suppressor Kinase 1(LATS1) and EGFR-ERK pathway, and its molecular targets CTGF, WTN5A and EMP2 in in human PDA cells. Cells were extracted in 1\% SDS buffer containing protease and phosphatase inhibitors (Sigma Aldrich). Nuclear protein extracts were obtained from cell monolayers with the Nuclear Extract Kit (Active Motif Corp., Carlsbad, CA, USA). Protein concentrations were determined using the Bradford Assay Kit (Bio-Rad Hercules, CA, USA). Nuclear protein levels of YAP1 and cellular protein levels of total and EGFR phosphorylated at Tyr1068 (p-EGFR), total and p-ERK 1/2 and LATS1, a key kinase of the Hippo pathway [32], were assessed by Western blotting (see Supplementary Table S1 for antibodies in Additional file 1). KRAS activity was evaluated by the KRAS activation Assay Kit (no. STA-400-K Cell Biolabs, Inc.) according to the manufacturer's protocol. Briefly, $1 \mathrm{mg}$ of lysate was subjected to pull-down and $50 \mu \mathrm{g}$ of lysate was used to measure total KRAS. Pull-down and total lysates were subjected to Western blotting procedure using the primary antibody against KRAS provided by the kit. The mRNA levels of CTGF/CCN2, WTN5A and EMP2, three recognized molecular targets of YAP [23, 33, 34], were assessed by realtime PCR (RT-PCR) using a StepOne Real-Time PCR System and TaqMan Gene Expression assays (Thermo Fisher Scientific) [10] listed in Supplementary Table S3 (see Additional file 1).

\section{Statistical analysis}

Results are expressed as mean $\pm \mathrm{SD}$, mean \pm SEM or percentage. Differences between cell types/treatments or animal groups were assessed by one-way ANOVA followed by the Student-Newman-Keuls test for multiple comparisons, or two-way ANOVA followed by the Bonferroni post-test, as appropriate. Betweengroup differences in $\mathrm{PaC}$ incidence were assessed using the Chi-squared test and Fisher's exact test to compute a $P$-value from a contingency table. A $P$ value of $<0.05$ was considered to be significant. All statistical tests, including linear regression analysis, were performed on raw data using GraphPad Prism version 5.00 for Windows (GraphPad Software, San Diego, CA, USA).

\section{Results}

\section{In vivo study}

\section{Metabolic parameters}

STZ-treated KCM mice developed hyperglycaemia starting about $72 \mathrm{~h}$ post-injection (Fig. 2a) and showed a slight decline in the growth curve vs $\mathrm{Ctr}$ mice, which reached statistical significance only at 8 and 12 weeks of age (Fig. 2b). Despite no difference in body weight (Fig. 2c), blood glucose (Fig. 2d), and HbA1c levels (Fig. 2e), FL-926-16 treatment prevented the diabetes-associated increase in circulating AGEs (Fig. 2f) and total PCOs (Fig. 2g), as assessed at the end of the study.

Invasive PaC development Representative BLI images at the end of the study period and total photon flux induction from pancreas at 6,11 , and 22 weeks of age are shown in Fig. 3a. At sacrifice, pancreas weight was significantly $(P<0.01)$ increased in Diab $(0.82 \pm$ $0.29 \mathrm{~g})$ vs Ctr $(0.38 \pm 0.14 \mathrm{~g})$ and vs Diab+FL $(0.44 \pm$ $0.27 \mathrm{~g}) \mathrm{KCM}$ mice. Pancreas/body weight percent ratio was almost tripled in Diab vs Ctr mice, whereas no statistical difference was observed between Diab+FL and Ctr mice (Fig. 3b and Table 1). As assessed by histology (Fig. 3c), cumulative incidence of invasive $\mathrm{PaC}$ at 22 weeks of age was $75 \%$ in Diab mice vs $25 \%$ in Diab-FL and $8.3 \%$ in Ctr mice (Fig. $3 \mathrm{~d}$ and Table 1). Representative BLI images and pancreas histology from Ctr, Diab and Diab+FL are shown in Fig. 3c-d. Neither the Ctr + FL nor the STZ-non-Diab group showed significant differences in the incidence invasive $\mathrm{PaC}$ and pancreas/body weight percent ratio vs the Ctr group (Table 1). Furthermore, no betweengroup differences were observed in tumour invasiveness, except for an apparent reduction in Diab+FL vs Diab group (Table 1). However, the few cases of $\mathrm{PaC}$ in Diab+FL $(n=3)$ and Ctr $(n=1)$ mice prevent to perform statistical comparisons among groups for metastatic disease. Representative ex vivo BLI and histology images of liver and lung metastases are presented in Supplementary Fig. S1 in Additional file 1. Grading of dysplastic ducts in mice free of invasive $\mathrm{PaC}$ (Table 2) showed significant differences between Diab+FL and Diab mice for the percentage of normal ducts, which was higher, and of high-grade PanINs, which was lower, in the FL-926-16- treated arm. In addition, Ctr + FL mice presented with higher normal ducts and lower low-grade PanINs vs Ctr mice, whereas no difference was observed between STZnon-Diab and Ctr mice.

Pancreatic AGEs ERK 1/2 phosphrylation status, nuclear YAP, and connective tissue growth factor (CTGF). Pancreatic accumulation of AGEs (Fig. 4a) and levels p-ERK 1/2 (Fig. 4b), CTGF (Fig. 4c), a well-established transcriptional target of YAP [24, 33, 34], and nuclear YAP1 (Fig. 4d) were increased in Diab vs Ctr mice and increments were prevented by 
A

Blood glucose

B Body weight
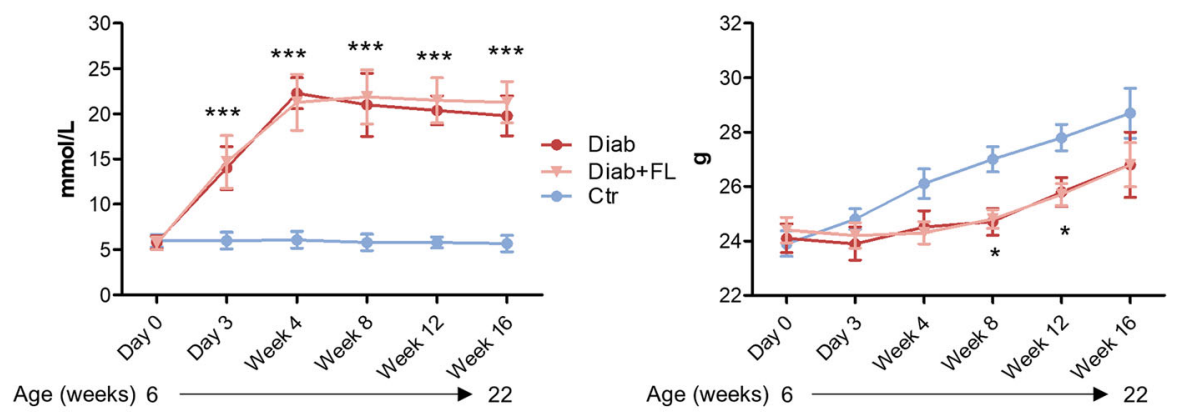

C

Body weight

D Blood glucose

E

HbA1Ac

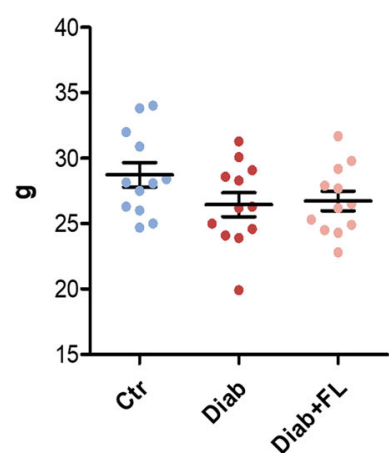

F

Serum AGEs

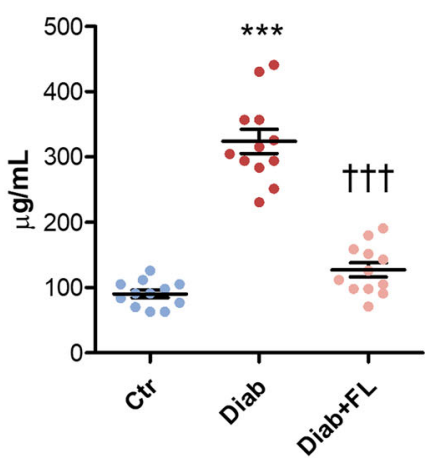

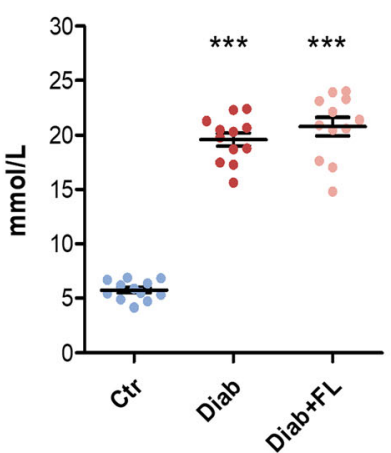

G

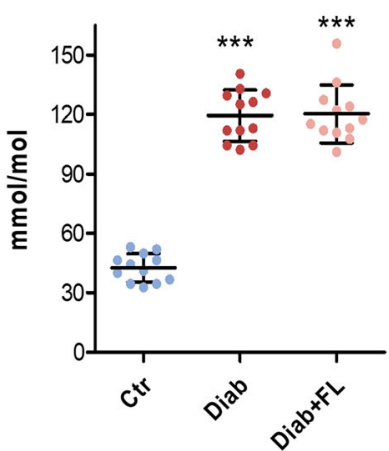

Serum PCOs

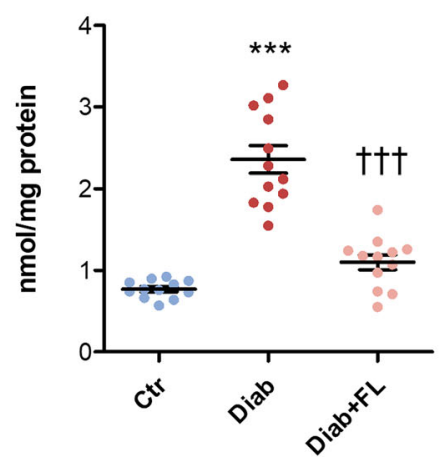

Fig. 2 Glucose and HbA1c levels, body weight and hyperglycaemia-associated carbonyl stress. Blood glucose levels and body weight during the study period ( $\mathbf{a}$ and $\mathbf{b}$ ) and at the end of the study period (22 weeks of age ${ }^{7}$ ) (c and $\mathbf{d}$ ) and HbA1c levels (e), and serum levels of AGEs (f) and total PCOs ( $\mathbf{g}$ ) at the end of the study period (22 weeks of age ${ }^{\mathbf{1}}$ ) in control (Ctr), Ctr treated with FL-926-16 (Ctr + FL), diabetic (Diab), and Diab treated with FL-926-16 (Diab+FL) KCM mice. Statistical significance between groups for time course of blood glucose (a) and body weight (c) was calculated using two-way ANOVA followed by the Bonferroni post-test. Each time point represents mean \pm SD of 12 animals until the 17th week of age, and 9-12 animals from the 18th to the 22nd week of age. Statistical significance for blood glucose (c), body weight (d), serum levels of AGEs (e) and PCOs (f) at 22 weeks of age ${ }^{1}$ was assessed using one-way ANOVA followed by the Student-Newman-Keuls test for multiple comparisons. Each dot represents one case and bars represent mean \pm SEM. ${ }^{* *} P<0.001$ or ${ }^{*} P<0.05$ vs Ctr; $\dagger++P<0.001$ vs Diab. ${ }^{1}$ Except for three Diab and one Diab +FL mice, which were killed 5 and 3 weeks, respectively, before the end of the study (see "Results" section for further details).

FL-926-16 treatment. Dual label immunofluorescence analysis confirmed the association between AGEs and nuclear YAP1 in PaC lesions from Diab mice (Fig. 4e). A significant positive relationship between AGE accumulation and nuclear YAP1 levels was also observed in human PDA (Fig. 4f-g).

\section{In vitro study}

\section{Proliferation of human PDA cells}

HG concentration mimicking diabetic hyperglycaemia promoted PDA cell growth and this effect was prevented by FL-926-16 (Fig. 5a-b). The AGE precursors RCS, MGO and GO, and the preformed AGE 


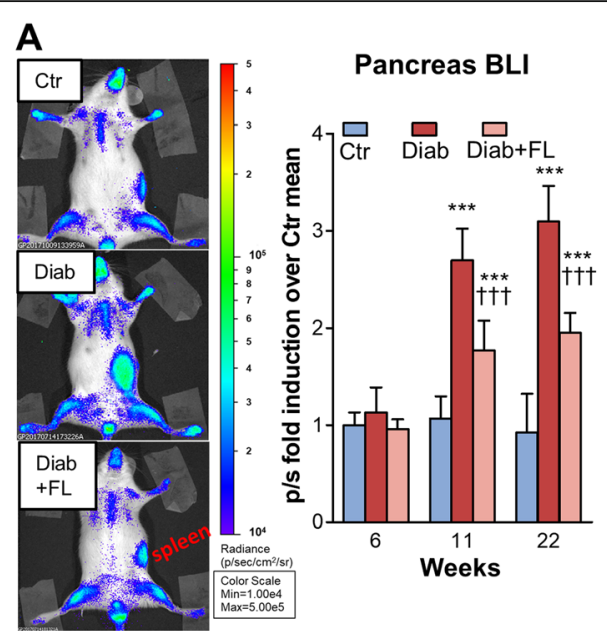

B

Pancreas/Body weight

C

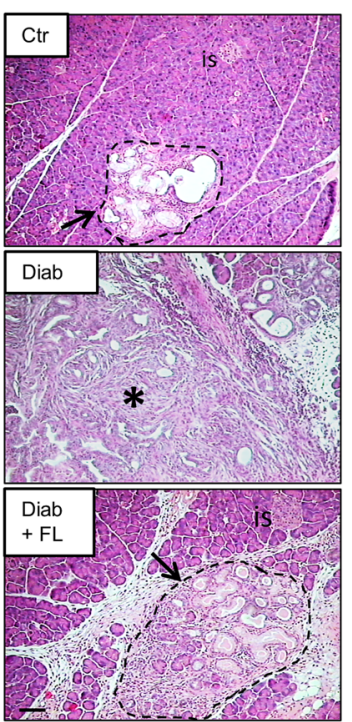

D

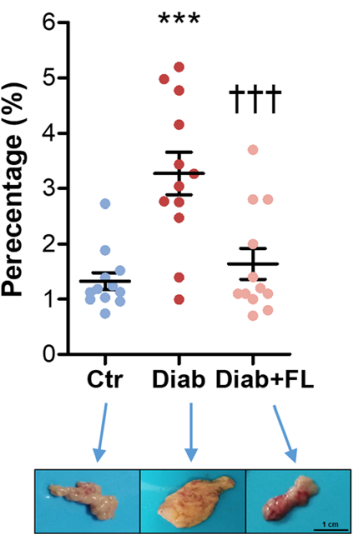

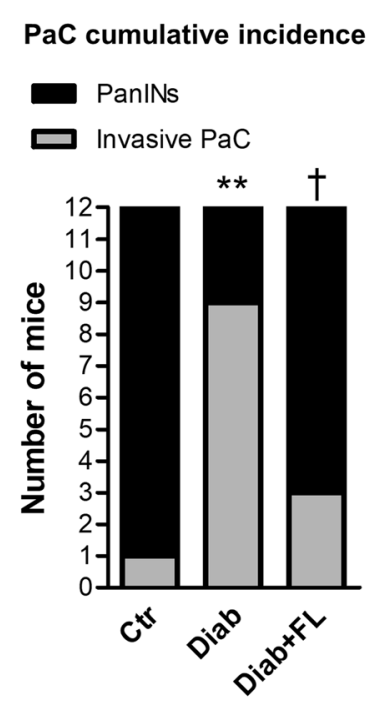

Fig. 3 In vivo BLI and gross and microscopic examination of pancreas. Representative BLI at the end of the study period and total photon flux $(\mathrm{p} / \mathrm{s})$ induction from pancreas at 6, 11 and 22 weeks of age ${ }^{\mathbf{1}}$ (a), pancreas/body weight percent ratio (b), representative pancreas histology (c, original magnification: 100X, scale bar: 200 mm), and cumulative incidence of PaC (d) in control (Ctr), diabetic (Diab), and Diab treated with FL926-16 (Diab+FL) KCM mice at the time of sacrifice. Statistical significance between groups for pancreas/body weight percent ratio (a) was calculated using one-way ANOVA followed by the Student-Newman-Keuls test for multiple comparisons. Each dot represents one case and bars represent mean \pm SEM. Statistical significance for PaC incidence $(\mathbf{b})$ was assessed using the Chi-squared test and Fisher's exact test. ${ }^{* *} P<0.01$ vs $\mathrm{Ctr} ;+P<0.05$ vs Diab. Is = islet, ${ }^{*}=$ invasive PaC, arrows = PanINs. ${ }^{1}$ Except for three Diab and one Diab $+F L$ mice, which were killed 5 and 3 weeks, respectively, before the end of the study (see "Results" section for further details).

CML also stimulated PDA cell proliferation. FL-92616 was able to inhibit cell proliferation induced by MGO and GO, but not CML (Fig. 5c). Treatment with CML, but not with MGO, induced ERK $1 / 2$ activation, and FL-926-16 was ineffective in counteracting the effect of CML on ERK $1 / 2$ phosphorylation status (Fig. 5d). However, the proliferating effect of both the RCS MGO and the AGE CML was associated with YAP1 nuclear persistence and activity. Again, FL-926-16 efficiently prevented the nuclear translocation of YAP1 induced by MGO, but failed to counteract the effect of CML (Fig. 5e). Consistently, FL-926-16 treatment reversed the MGOinduced upregulation of gene expression of CTGF, Wnt Family Member 5A (WNT-5A) and Epithelial Membrane Protein 2 (EMP2), three well-recognized YAP target genes [24, 33, 34]. Conversely, FL-926-16 was ineffective in preventing the modulatory effect of CML on the mRNA level of these genes (Supplementary Fig. S2 in Additional file 1). 
Table 1 Pancreatic cancer (PaC) incidence, Pancreas/Body weight $(\mathrm{Wt})$ percent ratio and metastasis

\begin{tabular}{llll}
\hline & $\mathrm{PaC}$ N/tot & Pancreas/Body Wt $\%$ & Metastasis N/tot PaC \\
\hline Ctr & $1 / 12$ & $1.3 \pm 0.5$ & $1 / 1$ \\
Diab $^{\mathbf{1}}$ & $9 / 12$ & $3.3 \pm 1.3^{* * *}$ & $8 / 9$ \\
Diab + FL & $3 / 12$ & $1.6 \pm 1.0+\dagger \dagger$ & $1 / 3$ \\
Ctr + FL & $1 / 9$ & $1.4 \pm 0.5$ & $1 / 1$ \\
STZ-non-Diab & $1 / 9$ & $1.3 \pm 0.4$ & $0 / 1$ \\
\hline
\end{tabular}

Cumulative incidence of $\mathrm{PaC}$ and Pancreas/Body weight $(\mathrm{Wt})$ percent ratio in control (Ctr), diabetic (Diab), Diab treated with FL-926-16 (Diab+FL), Ctr treated with FL-926-16 (Ctr + FL) and streptozotocin-treated non-diabetic (STZ-nonDiab) KCM mice at the end of the study ( 16 weeks of diabetes, 22 weeks of $\mathrm{age}^{1}$ ). The number of KCM mice with metastasis (liver and or lung) on the total number of $\mathrm{PaC}$ cases is also shown. $\mathrm{KCM}=L \mathrm{LL}-\mathrm{Kras}^{\mathrm{G}}{ }^{2 \mathrm{D} /+} ; \mathrm{Pdx}-1-\mathrm{Cre} ; \mathrm{MITO}$ $\mathrm{N} /$ tot $=$ number of cases/total number of mice; $\mathrm{N} /$ tot $\mathrm{PaC}=$ number of cases $/$ total number of $\mathrm{PaC} . \mathrm{PaC}$ (ductal adenocarcinoma) and hepatic and/or lung metastasis were confirmed by histology. ${ }^{* *} P<0.001$ or ${ }^{* *} P<0.01$ vs $C$ tr; $+++P<0.001$ or $+P<0.05$ vs Diab. Statistical significance between groups for Pancreas/Body Weight percent ratio was calculated using one-way ANOVA followed by the Student-Newman-Keuls test for multiple comparisons. Statistical significance for $\mathrm{PaC}$ rate was assessed using the Chi-squared test and Fisher's exact test

${ }^{1}$ Except for three Diab and one Diab + FL mice, which were killed 5 and 3 weeks, respectively, before the end of the study

\section{Mechanisms underlying RCS- and AGE-induced YAP activation}

Silencing of YAP1 using two independent siRNAs (siYAP\#1 and \#2) (Fig. 6a) significantly inhibited the transcription activity of YAP target genes induced by both MGO and CML in PDA cells (Fig. 6b). In MGO-treated cells, YAP induction was associated with a decrease in protein levels of LATS1, a well-established negative regulator of YAP activity [32], whereas CML treatment failed to modulate LATS1 (Fig. 6c). Instead, treatment with CML, but not with MGO, was found to induce EGFR phosphorylation (pEGFR) (Fig. 6d). EGFR silencing (Fig. 6e) almost completely reversed YAP1 nuclear translocation (Fig. 6f), KRAS activation, and ERK 1/2 phosphorylation (Supplementary Fig. S3A-B) induced by CML.

\section{Effects of serum from diabetic patients on proliferation of} human PDA cells

The levels of AGEs were $178.2 \pm 13.2 \mu \mathrm{g} / \mathrm{mL}$ in the pooled sera from diabetic patients and $72.3 \pm 4.54 \mu \mathrm{g} / \mathrm{mL}$ in pooled sera from non-diabetic individuals. The diabetic serum induced a 3 -fold increase in PDA cell proliferation compared to the non-diabetic serum. This effect was greatly reduced by prior selective AGE removal from the diabetic serum (AGE levels, 95.5 $\pm 7.92 \mu \mathrm{g} / \mathrm{mL}$ ) and almost completely reversed by combining AGE removal from serum and FL-926-16 treatment of PDA cells (Fig. 7).

\section{Discussion}

Despite the epidemiological evidence of increased $\mathrm{PaC}$ risk in both type 1 [6] and $2[4,5]$ diabetes, the underlying mechanisms still remains to be elucidated. Here we showed that STZ-induced type 1 diabetes, which is characterized by marked hyperglycaemia and insulinopenia without weight gain [35], significantly accelerated tumour progression in a mouse model of Kras-driven $\mathrm{PaC}$. The absence of obesity and insulin resistance argues in favour of the hypothesis that the $\mathrm{PaC}$-promoting effect of diabetes is directly related to the adverse effects of hyperglycaemia. In addition, RCS trapping and AGE inhibition by FL-926-16 efficiently prevented the acceleration of PanIN progression to invasive $\mathrm{PaC}$ induced by diabetes. The difference in the incidence of $\mathrm{PaC}$ between the two diabetic groups (i.e., untreated and treated with FL926-16) occurred despite similar increases of blood glucose levels, supporting the concept that glucose metabolites, but not glucose per se, were responsible for $\mathrm{PaC}$ promotion. STZ-treated mice that failed to develop or reversed hyperglycaemia showed the same $\mathrm{PaC}$ incidence as the $\mathrm{Ctr}$ group, thus ruling out an effect of STZ on invasive $\mathrm{PaC}$ development in Diab mice.

Our finding of an association between AGE accumulation and YAP induction in $\mathrm{PaC}$ in Diab mice is

Table 2 Pancreatic intraepithelial neoplasia (PanIN) grading

\begin{tabular}{llll}
\hline & Normal ducts \% & Low-grade PanINs \% & High-grade PanINs \% \\
\hline Ctr $(n=11)$ & $68.0 \pm 7.3$ & $26.6 \pm 5.4$ & $5.4 \pm 5.6$ \\
Diab $(n=3)$ & $31.7 \pm 10.5 * *$ & $42.0 \pm 6.6 * * .3$ & $26.3 \pm 14.22 * *$ \\
Diab + FL $(n=9)$ & $51.3 \pm 5.9 *+\dagger$ & $37.4 \pm 7.3 * *$ & $11.2 \pm 4.3+\dagger$ \\
Ctr + FL $(n=8)$ & $77.0 \pm 6.2 *+\dagger$ & $20.4 \pm 5.6 *++$ & $2.6 \pm 1.5++$ \\
STZ-non-Diab $(n=8)$ & $61.6 \pm 9.7+\dagger$ & $32.4 \pm 7.4$ & $6.6 \pm 5.2++$ \\
\hline
\end{tabular}

PanIN grading in control (Ctr), diabetic (Diab), Diab treated with FL-926-16 (Diab+FL), Ctr treated with FL-926-16 (Ctr + FL) and streptozotocin-treated non-diabetic (STZ-non-Diab) KCM mice free of invasive pancreatic cancer as attested by histology at the end of the study (16 weeks of diabetes, 22 weeks of age). KCM $=$ LSLKras ${ }^{G 12 D /+} ; P d x-1-C r e ;$ MITO. ${ }^{* *} P<0.01$ and ${ }^{*} P<0.05$ vs Ctr; $+\dagger P<0.01$ vs Diab. Statistical significance between groups for Normal ducts, Low-grade (PanlN-1A/B) and High-grade (PanIN-2/3) dysplastic ducts was calculated using one-way ANOVA followed by the Student-Newman-Keuls test for multiple comparisons 

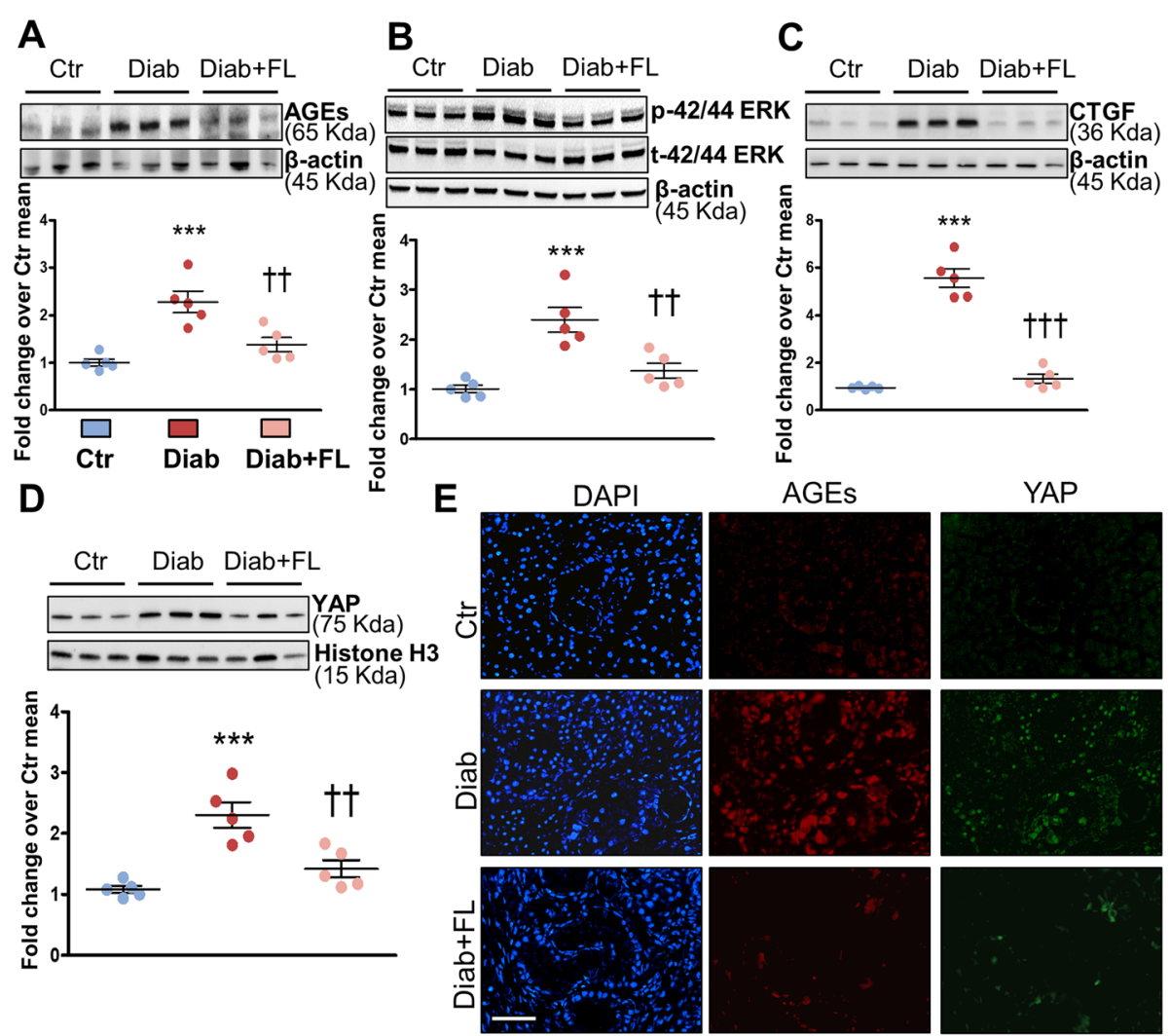

$\mathbf{F}$

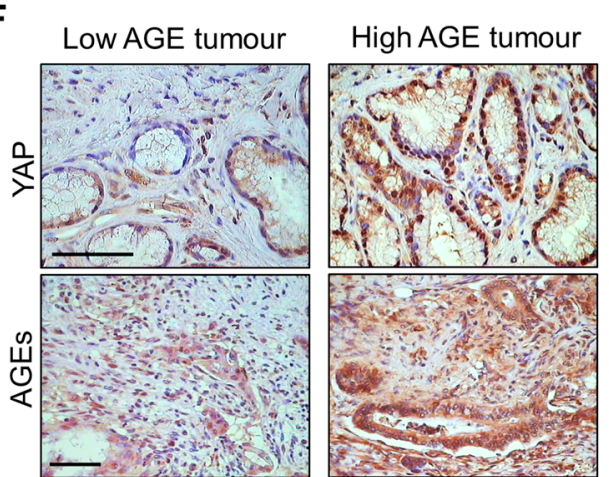

G

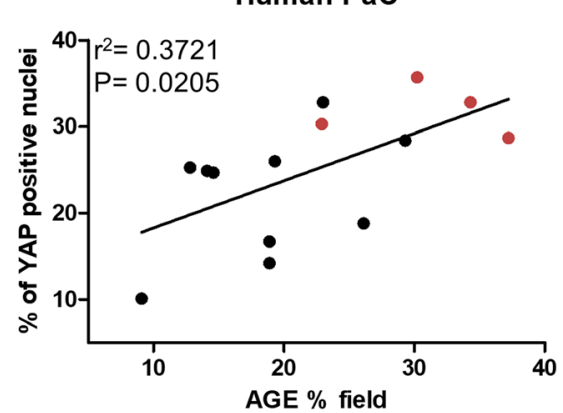

Fig. 4 Association between AGE levels (carbonyl stress burden), ERK 1/2 phosphorilation status and YAP activation in murine and human PaC. Representative Western blots for AGEs (a), phosphorylated and total ERK 1/2 (b), CTGF (c) and nuclear YAP (d) in control (Ctr), diabetic (Diab), and Diab treated with FL-926-16 (Diab+FL) KCM mice at the time of sacrifice and relative band densitometry analysis from five mice per group. Each dot represents one case and bars represent mean \pm SEM. Dual-label immunofluorescence (d) for AGEs (red) and YAP (green). DAPI (blue): 4',6diamidino-2-phenylindole. Original magnification: 250X, scale bar: $200 \mu \mathrm{m}$. Active (non-phosphorylated) YAP immunohistochemistry staining (e, upper panels, original magnification: 400X, scale bar: $200 \mu \mathrm{m}$ ) in representative low and high carbonyl stress human pancreatic adenocarcinomas as assessed by their AGE level (e, lower panels, original magnification: 250X, scale bar: $200 \mu \mathrm{m}$ ). Linear regression analysis (f) of the correlation between the ratio of YAP-positive nuclei to total nuclei with percentage of tumour tissue positive for AGE staining $(n=14)$. Red dots $=$ patients with a clinical diagnosis of diabetes mellitus prior to undergoing surgery; black dots = non-diabetic subjects. Post hoc multiple comparison: ${ }^{* * *} P<0.001$ vs $C$ tr $;+\uparrow+P<0.001$ or $+\uparrow P<0.01$ vs Diab

in line with previous evidence of a role of carbonyl stress in breast cancer [23, 36]. In this tumour type, a high content of RCS protein adducts (i.e., AGEs) was found to be associated with increased nuclear levels of the transcriptional co-activator YAP [23, 36], a key regulator of tumour growth and invasion
$[24,25,33,37]$. This finding is consistent with the observation that cellular glucose metabolism stimulates YAP activity $[38,39]$ through the production of the glycolysis side-product MGO [39]. Hence, from a mechanistic perspective, the high glycolytic rates of cancer cells would favour formation of MGO and 


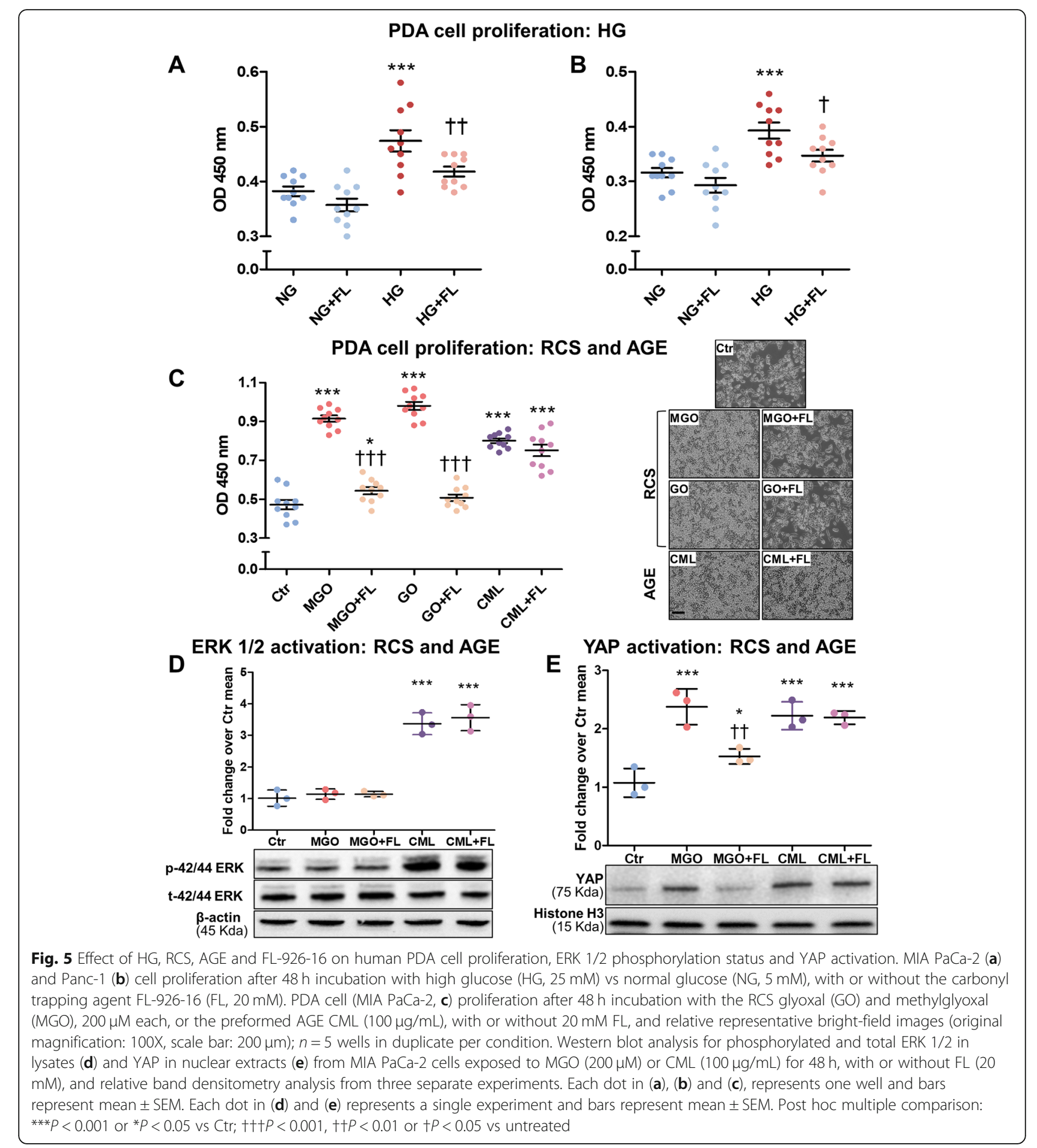

other RCS, since they are inevitably generated as byproducts of glycolysis [11, 23, 40, 41]. In turn, RCS and their protein adducts (i.e., AGEs) would promote YAP nuclear localization and activity. It was proposed that variability in carbonyl stress burden among different tumour subtypes may partly depend on differences in enzymatic detoxification rates of MGO [36]. However, enhanced carbonyl stress burden and consequent tumour accumulation of AGEs in diabetes may depend mainly on the accelerated production rate of RCS favoured by the unrestricted availability of glucose to glycolysis-dependent cancer 
B
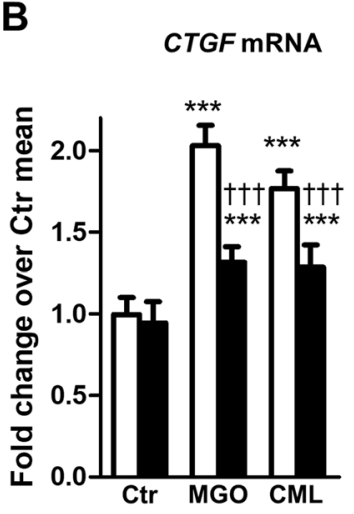

$C$

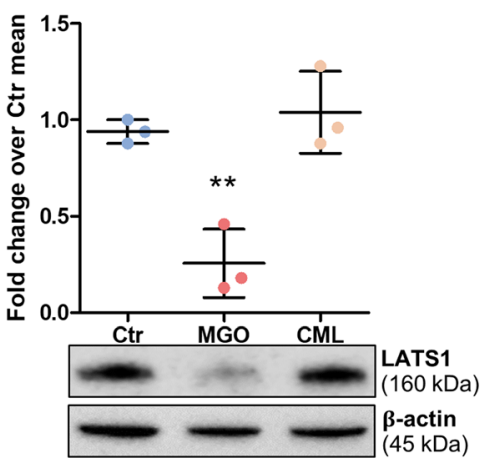

E

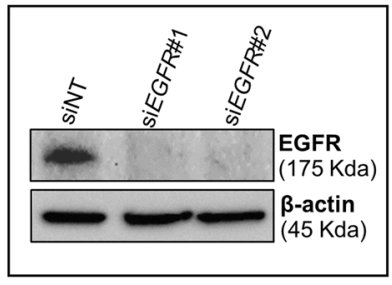

$F$
A

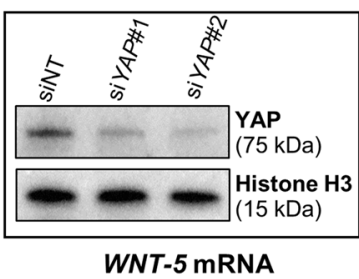

WNT-5 mRNA
EMP2 MRNA

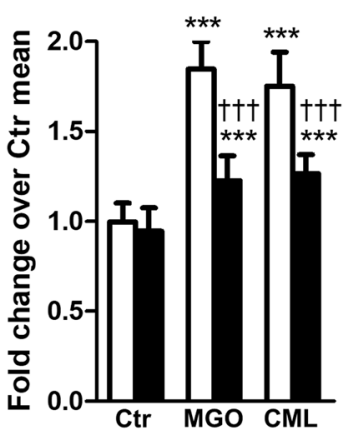

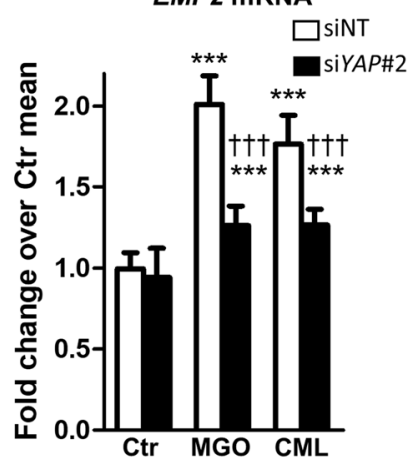

D
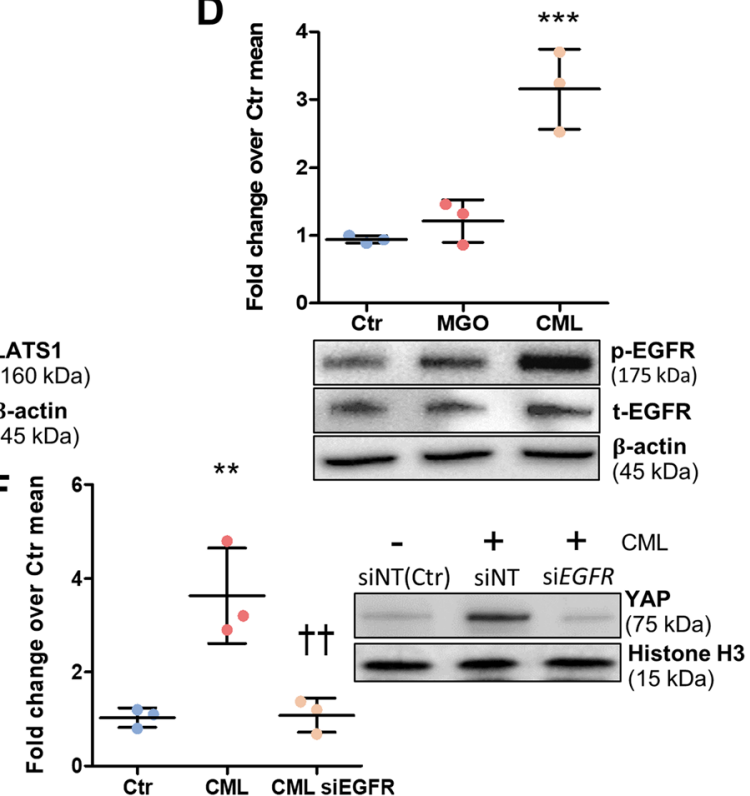

Fig. 6 Differential mechanisms underlying RCS- and AGE-induced YAP activation. YAP protein level (a) by Western blot in MIA PaCa-2 siNT control and siYAP\#1 and \#2 cells after 48 h. CTGF, WNT5a and EMP2 mRNA levels (b) in MIA PaCa-2 siNT control and siYAP\#2 cells exposed to MGO $(200 \mu \mathrm{M})$ or CML $(100 \mu \mathrm{g} / \mathrm{mL}) ; \mathrm{n}=5$ wells in duplicate per condition. LATS1 (c) and total and phosphorylated EGFR (d) levels in MIA PaCa-2 cells exposed to MGO $(200 \mu \mathrm{M})$ or CML $(100 \mu \mathrm{g} / \mathrm{mL})$ for $48 \mathrm{~h}$ and relative band densitometry analysis from three separate experiments. Analysis of EGFR silencing by Western blot (e) in MIA PaCa-2 cells after $48 \mathrm{~h}$. Western blot analysis for YAP (f) in nuclear extracts from MIA PaCa-2 siNT control and siEGFR cells exposed to CML $(100 \mu \mathrm{g} / \mathrm{mL})$ for $48 \mathrm{~h}$ and relative band densitometry analysis from three separate experiments. Each dot represents a single experiment and bars represent mean \pm SD. Post hoc multiple comparison: ${ }^{* *} P<0.001,{ }^{* *} P<0.01$ or ${ }^{*} P<0.05$ vs Ctr; $+++P<$ 0.001 or $++P<0.01$ vs treated (MGO or CML) siNT control. siNT = non-target control

cells. In addition, the increased systemic carbonyl stress and circulating RCS/AGE levels characterizing diabetes $[42,43]$ may also contribute to the progression of preneoplastic lesions (Fig. 8), as also indicated by our previous study [10].

We demonstrated that AGE accumulation is associated with higher nuclear YAP levels and activity also in human $\mathrm{PaC}$ specimens. These results, together with the finding that treatment with FL-926-16 was able to counteract the diabetes promoting effect on invasive $\mathrm{PaC}$ development, support the hypothesis that hyperglycaemia-induced carbonyl stress is a risk factor for increased incidence of $\mathrm{PaC}$ in the diabetic population, in line with the recent epidemiological observation 


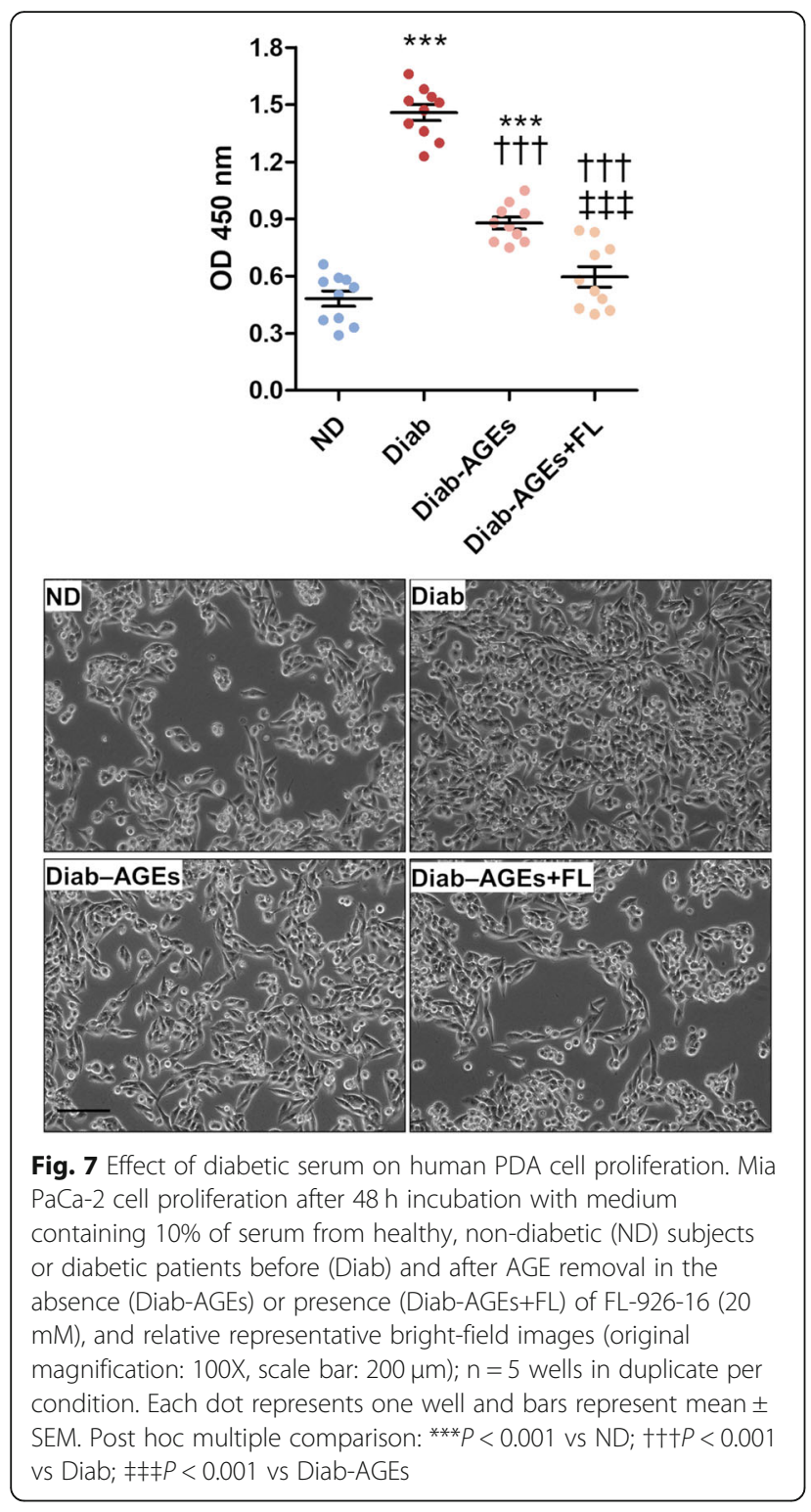

that the risk of $\mathrm{PaC}$ increases linearly with increasing fasting glucose levels [7].

In vitro experiments provided further mechanistic insight into the role of carbonyl stress in diabetesinduced $\mathrm{PaC}$ promotion. First, the ability of diabetic serum to induce human PDA cell growth was significantly inhibited by prior selective AGE removal, confirming our previous observation that circulating AGEs can exert a promoting effect on tumour progression [10]. The residual proliferating effect of diabetic serum after AGE removal was attributable to serum factors favouring RCS formation (e.g., high glucose) in cancer cells, as indicated by the additional protection provided by FL-926-16, and supported by the finding that FL-926-16 prevented HG- induced PDA cell growth. Consistently, both preformed AGEs and their RCS precursors stimulated PDA cell proliferation, YAP nuclear translocation, and upregulation of its target genes. FL-926-16 treatment was effective in preventing cell proliferation and YAP activation induced by HG and RCS but, as expected, failed to provide protection when cells were incubated with preformed AGEs. Overall, these in vitro results are in agreement with the RCSscavenging action of FL-926-16 $[15-19,21]$ and indicate that the cell growth effect induced by HG is mediated by both RCS and AGEs.

The role of YAP as a mediator of the effects exerted by RCS and AGEs was attested by the silencing experiments targeting this transcription regulator, which was previously shown to be critical in progression to $\mathrm{PaC}$ [24] and in MGO-induced breast tumour growth [23]. However, while the AGE precursors RCS were found to reduce Large Tumour Suppressor Kinase 1 levels, a negative regulator of YAP activity, the effect of AGEs on YAP induction was completely dependent on EGFR/ERK signalling (Fig. 8). The results of the EGFR silencing experiments are in line with previous studies showing the ability of AGEs to transactivate the EGFR [44, 45], the role of EGFR ligands in sustaining YAP activity, and the association of EGFR ligands with shorter overall survival in human $\mathrm{PaC}[33,46]$. The observation that AGEs induce EGFR phosphorylation in PDA cells takes on pathological relevance, as Kras-driven $\mathrm{PaC}$ growth was shown to be dependent on EGFR signalling $[47,48]$, and combined inhibition of EGFR and C-RAF led to complete regression of $\mathrm{PaC}$ [49]. Finally, the effect of MGO on LATS1 is in keeping with the previous finding that MGO favours proteasome degradation of this tumour suppressor [23].

The main strength of this study is the use of a type 1 diabetes model, which allowed us to evaluate the effect of hyperglycaemia on invasive $\mathrm{PaC}$ development independently of other confounders while accounting for the effect of STZ per se by including the STZnon-Diab group. A possible limitation is the use of immunological instead of analytical techniques for assessing AGE levels. However, this approach allowed us to evaluate the overall AGE burden (i.e., carbonyl stress) and the tissue distribution of these byproducts, whereas the effect of individual RCS and AGE structures were investigated in the in vitro experiments.

\section{Conclusions}

This study shows that diabetes-associated hyperglycemia promotes PanIN progression to invasive $\mathrm{PaC}$. FL-926-16, a selective RCS scavenger and AGE inhibitor, prevented the accelerating effect of diabetes 


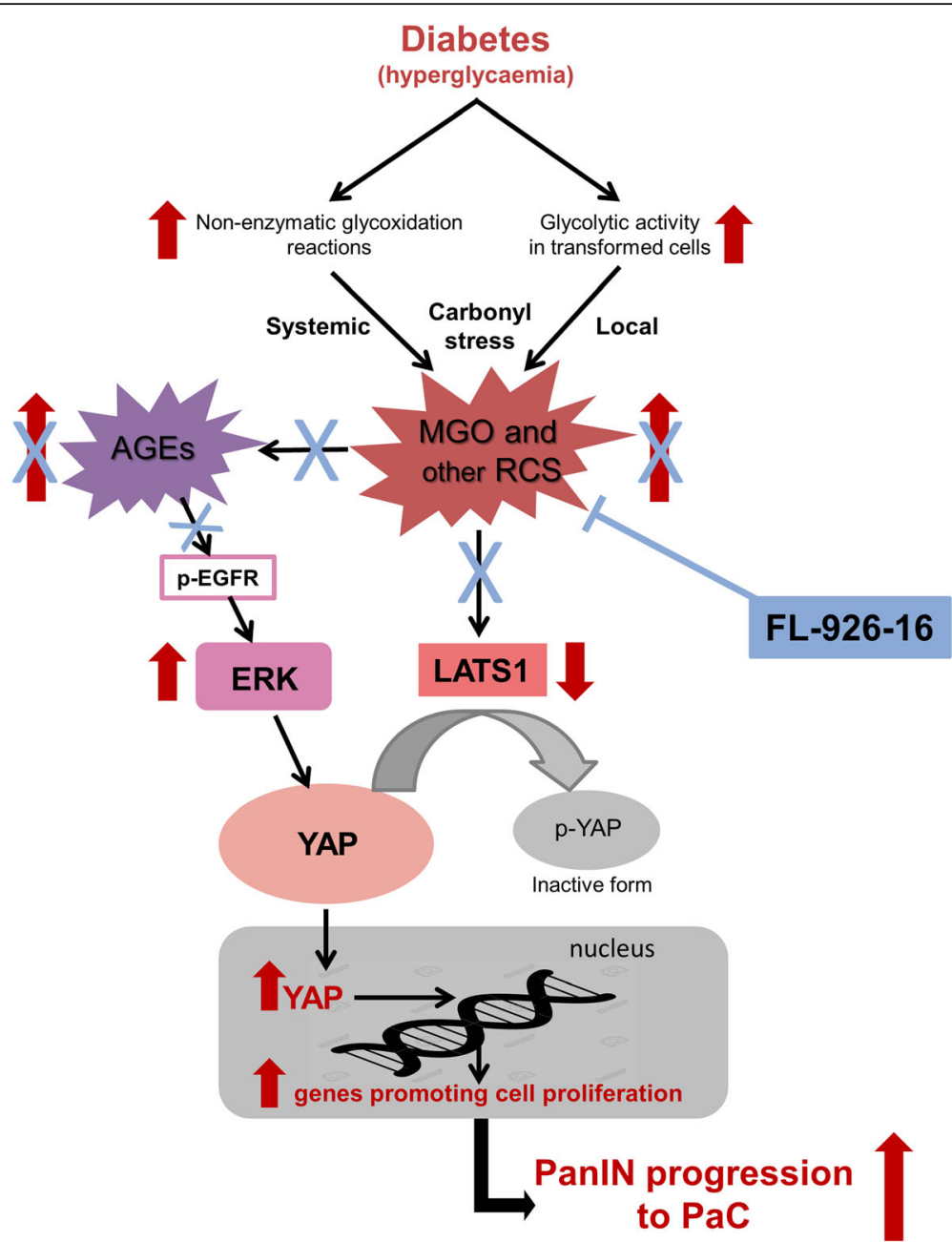

Fig. 8 Carbonyl stress in PaC promotion induced by diabetes and mechanism of FL-926-16-mediated protection. Diabetes markedly accelerates tumour progression through hyperglycaemia-derived carbonyl stress. The increased availability of glucose feeds the glycolytic flux of tumour cells favouring local formation of RCS such as MGO, an inevitable side-product of glycolysis, and consequent AGE accumulation. In addition, circulating RCS and their protein adducts (i.e., AGEs) derived from non-enzymatic glycoxidation reactions occurring at the systemic level may also contribute to AGE accumulation in neoplastic lesions, which is associated with increased nuclear translocation of YAP, a key effector of Hippo pathway and regulator of tumour growth and invasion $[24,25,34,37]$. Quenching of RCS and inhibition of AGE formation by the RCS sequestering agent FL926-16 efficiently prevents hyperglycaemia-induced YAP activation and acceleration of PanIN progression to invasive PaC. LATS1 = large tumour suppressor kinase 1; ERK = extracellular signal-regulated kinase; $\mathrm{p}$-EGFR = phosphorylated epidermal growth factor receptor; $\mathrm{p}-\mathrm{YAP}=$ phosphorylated $\mathrm{YAP}$

on PanINs progression to invasive $\mathrm{PaC}$ and $\mathrm{PDA}$ cell proliferation, providing evidence of the involvement of carbonyl stress in the association between diabetes and increased risk of $\mathrm{PaC}$. Overall, our study proposes a general molecular mechanism underlying the diabetes-cancer link and suggests that carnosinaseresistant carnosine derivatives represent a promising class of RCS-scavenging agents that might be useful not only in the treatment of metabolic disorders [18, 19] and their complications [21, 22], but also in risk management and prevention of cancer, particularly in high-risk diabetic individuals.

\section{Supplementary information}

Supplementary information accompanies this paper at https://doi.org/10. 1186/s13046-020-01665-0.

Additional file 1. Supplementary Table S1. Antibodies used in Western blot and IHC studies. Supplementary Table S2. Silencer select Validated/ Predesigned siRNAs and related TaqMan assays. Supplementary Table S3. TaqMan Gene Expression assays. Supplementary Fig. S1. Color digital photo (A), ex vivo BLI (B) and histological analysis (C) of the lung (left) and the liver (right) of a Diab KCM mice with metastatic PaC.

Supplementary Fig. S2. Effect of RCS, AGE and FL-926-16 on YAP activity. Supplementary Fig. S3. Effect of EGFR silencing on KRAS activity and pERK $1 / 2$ levels in human PDA cells exposed to CML. 


\section{Abbreviations}

AGEs: Advanced glycation end-products; BLI: Bioluminescence imaging; CML: $N^{\varepsilon}$-carboxymethyllysine; CTGF: Connective tissue growth factor gene; Ctr: Non-diabetic control mice; Ctr + FL: Non-diabetic control mice treated with FL-926-16; Diab: Diabetic mice; Diab+FL: Diabetic mice treated with FL926-16; EGFR: Epidermal growth factor receptor; EMP2: Epithelial membrane protein 2 gene; ERK: Extracellular signal-regulated kinase; FL-926-16: (2S)-2-(3amino propanoylamino)-3-(1 H-imidazol-5-yl) propanol (carnosinol); GO: Glyoxal; HG: High glucose; KC: Pdx1-Cre;LSL-Kras ${ }^{\text {G12D/+}}$; KCM: KC-Mito; MGO: Methylglyoxal; LATS1: large tumour suppressor Kinase 1; MITOLuC: Mitosis luciferase; PaC: Pancreatic cancer; PanIN: Pancreatic intraepithelial neoplasia; PCOs: Total protein carbonyls; PCR: Polymerase chain reaction; PDA: Pancreatic ductal adenocarcinoma; p-EGFR: Phosphorylated-EGFR; pERK: Phosphorylated extracellular signal-regulated kinase; RCS: Reactive carbonyl species; RT-PCR: Real-time PCR; siRNA: Small interfering RNAs; STZ: Streptozotocin; STZ-non-Diab: Streptozotocin-injected non-diabetic mice; WNT-5A: Wnt family member 5A gene; YAP: Yes-associated protein.

\section{Acknowledgements}

The Authors thank Flamma S.p.A. for the gift of FL-926-16 and Cinzia Cataldo for technical assistance in sample collection, coding and histology processing.

\section{Authors' contributions}

SM, Cl and GPu contributed to conception and design, acquisition of data, analysis and interpretation of data and drafting the article; CP contributed to acquisition and supervision of histological data and to the comparative analysis of IHC staining; MV contributed to acquisition of biochemical and molecular data; EP provided the human paraffin-embedded pancreatic adenocarcinoma specimens; FN and PC provided the genetically-engineered LSL-KrasG12D/+ and Pdx-1-Cre transgenic mice and contributed to critical revision of the article; GPi provided the genetically-engineered MITO-LUC mouse and supervised the design, execution and validation of BLI experiments; LdL and IM performed in vivo imaging of cell proliferation. The authors gave final approval of the version to be published.

\section{Funding}

This work was supported by a research grant from the Italian Association for Cancer Research (AIRC 2015; IG - 17640) to GP and Sapienza University of Rome - Progetti di Ateneo 2018 and 2019 to SM. The funding sources had no involvement in study design; in the collection, analysis and interpretation of data; in the writing of the report; and in the decision to submit the article for publication.

\section{Availability of data and materials}

The datasets used and/or analysed during the current study are available from the corresponding author upon reasonable request.

\section{Ethics approval and consent to participate}

The experimental protocols involving animals were approved by the National Ethics Committee for Animal Experimentation of the Italian Ministry of Health (Authorization no. 1470/2015-PR).

Informed consent was obtained from non-diabetic and diabetic individuals for experiment involving sera.

Human pancreatic ductal adenocarcinoma tissues were obtained from the Pathology Unit of the Sant'Andrea Hospital, Rome, Italy, in agreement with the ethical guidelines established by the locally appointed Ethics Committee.

\section{Consent for publication}

Not applicable.

\section{Competing interests}

The authors declare that they have no competing interests

\section{Author details}

'Department of Clinical and Molecular Medicine, "La Sapienza" University, Via di Grottarossa, 1035-1039 -, 00189 Rome, Italy. ${ }^{2}$ SAFU-unit, Department of Research, Advanced Diagnostics, and Technological Innovation, Regina Elena National Cancer Institute, Rome, Italy. ${ }^{3}$ Pathology Unit, University "La Sapienza", Sant'Andrea Hospital, Rome, Italy. ${ }^{4}$ DINOGMI, University of Genoa
Medical School, Genoa, Italy. ${ }^{5}$ Department of Molecular Biotechnology and Health Sciences, University of Turin, Turin, Italy.

Received: 30 March 2020 Accepted: 4 August 2020

Published online: 10 August 2020

\section{References}

1. Siegel RL, Miller KD, Jemal A. Cancer statistics, 2019. CA Cancer J Clin. 2019; 69:7-34.

2. Sohn TA, Yeo CJ, Cameron JL, Koniaris L, Kaushal S, Abrams RA, et al. Resected adenocarcinoma of the Pancreas-616 patients: results, outcomes, and prognostic indicators. J Gastrointest Surg. 2000;4:567-9.

3. Rahib L, Smith BD, Aizenberg R, Rosenzweig AB, Fleshman JM, Matrisian LM. Projecting cancer incidence and deaths to 2030: the unexpected burden of thyroid, liver, and pancreas cancers in the United States. Cancer Res. 2014; 74:2913-21.

4. Maisonneuve P, Lowenfels AB, Bueno-de-Mesquita HB, Ghadirian P, Baghurst PA, Zatonski WA, et al. Past medical history and pancreatic cancer risk: results from a multicenter case-control study. Ann Epidemiol. 2010;20: 92-8

5. Li D, Tang H, Hassan MM, Holly EA, Bracci PM, Silverman DT. Diabetes and risk of pancreatic cancer: a pooled analysis of three large case-control studies. Cancer Causes Control. 2011;22:189-97.

6. Carstensen B, Read SH, Friis S, Sund R, Keskimäki I, Svensson AM, et al. Cancer incidence in persons with type 1 diabetes: a five-country study of 9,000 cancers in type 1 diabetic individuals. Diabetologia. 2016:59:980-8.

7. Koo DH, Han KD, Park CY. The incremental risk of pancreatic cancer according to fasting glucose levels: Nationwide population-based cohort study. J Clin Endocrinol Metab. 2019;104:4594-9.

8. Chang HH, Moro A, Takakura K, Su HY, Mo A, Nakanishi M, et al. Incidence of pancreatic cancer is dramatically increased by a high fat, high calorie diet in KrasG12D mice. PLoS One. 2017;12:e0184455.

9. Philip B, Roland CL, Daniluk J, Liu Y, Chatterjee D, Gomez SB, et al. A highfat diet activates oncogenic Kras and COX2 to induce development of pancreatic ductal adenocarcinoma in mice. Gastroenterology. 2013;145: 1449-58.

10. Menini S, lacobini $C$, de Latouliere L, Manni I, lonta V, Blasetti Fantauzzi C, et al. The advanced glycation end-product N -carboxymethyllysine promotes progression of pancreatic cancer: implications for diabetesassociated risk and its prevention. J Pathol. 2018;245:197-208.

11. Schmitz J, Dittmar IC, Brockmann JD, Schmidt M, Hüdig M, Rossoni AW, et al. Defense against reactive carbonyl species involves at least three subcellular compartments where individual components of the system respond to cellular sugar status. Plant Cell. 2017;29:3234-54.

12. Ahmed N. Advanced glycation endproducts - role in pathology of diabetic complications. Diabetes Res Clin Pract. 2005:67:3-21.

13. Ellis EM. Reactive carbonyls and oxidative stress: potential for therapeutic intervention. Pharmacol Ther. 2007:115:13-24.

14. Aldini G, Facino RM, Beretta G, Carini M. Carnosine and related dipeptides as quenchers of reactive carbonyl species: from structural studies to therapeutic perspectives. Biofactors. 2005;24:77-87.

15. Menini S, lacobini C, Fantauzzi CB, Pugliese G. L-carnosine and its derivatives as new therapeutic agents for the prevention and treatment of vascular complications of diabetes. Curr Med Chem. 2019. https://doi.org/10.2174/ 0929867326666190711102718 [Epub ahead of print].

16. Regazzoni L, de Courten B, Garzon D, Altomare A, Marinello C, Jakubova M, et al. A carnosine intervention study in overweight human volunteers: bioavailability and reactive carbonyl species sequestering effect. Sci Rep. 2016;6:27224.

17. Baye E, Ukropec J, de Courten MPJ, Mousa A, Kurdiova T, Johnson J, et al. Carnosine supplementation improves serum resistin concentrations in overweight or obese otherwise healthy adults: a pilot randomized trial. Nutrients. 2018;10(9):1258.

18. Anderson EJ, Vistoli G, Katunga LA, Funai K, Regazzoni L, Monroe TB, et al. Carnosine analog mitigates metabolic disorders of obesity by reducing carbonyl stress. J Clin Invest. 2018;128:5280-93.

19. Haus JM, Thyfault JP. Therapeutic potential of carbonyl-scavenging carnosine derivative in metabolic disorders. J Clin Invest. 2018;128:5198-200.

20. Vistoli G, Carini M, Aldini G. Transforming dietary peptides in promising lead compounds: the case of bioavailable carnosine analogs. Amino Acids. 2012; 43:111-26. 
21. Menini S, lacobini C, Ricci C, Blasetti Fantauzzi C, Pugliese G. Protection from diabetes-induced atherosclerosis and renal disease by D-carnosineoctylester: effects of early vs late inhibition of advanced glycation endproducts in Apoe-null mice. Diabetologia. 2015;58:845-53.

22. lacobini C, Menini S, Blasetti Fantauzzi C, Pesce CM, Giaccari A, Salomone E, et al. FL-926-16, a novel bioavailable carnosinase-resistant carnosine derivative, prevents onset and stops progression of diabetic nephropathy in db/db mice. Br J Pharmacol. 2018;175:53-66.

23. Nokin MJ, Durieux F, Peixoto P, Chiavarina B, Peulen O, Blomme A, et al. Methylglyoxal, a glycolysis side-product, induces Hsp90 glycation and YAPmediated tumor growth and metastasis. Elife. 2016;5:e19375.

24. Zhang W, Nandakumar N, Shi Y, Manzano M, Smith A, Graham G, et al. Downstream of mutant KRAS, the transcription regulator YAP is essential for neoplastic progression to pancreatic ductal adenocarcinoma. Sci Signal. 2014;7(324):ra42

25. Gruber R, Panayiotou R, Nye E, Spencer-Dene B, Stamp G, Behrens A. YAP1 and TAZ control pancreatic cancer initiation in mice by direct up-regulation of JAK-STAT3 signaling. Gastroenterology. 2016;151:526-39.

26. Hingorani SR, Petricoin EF, Maitra A, Rajapakse V, King C, Jacobetz MA, et al. Preinvasive and invasive ductal pancreatic cancer and its early detection in the mouse. Cancer Cell. 2003;4:437-50.

27. Hruban RH, Adsay NV, Albores-Saavedra J, Anver MR, Biankin AV, Boivin GP, et al. Pathology of genetically engineered mouse models of pancreatic exocrine cancer: consensus report and recommendations. Cancer Res. 2006; 66:95-106

28. Goeman F, Manni I, Artuso S, Ramachandran B, Toietta G, Bossi G, et al. Molecular imaging of nuclear factor-Y transcriptional activity maps proliferation sites in live animals. Mol Biol Cell. 2012;23:1467-74.

29. de Latouliere L, Manni I, lacobini C, Pugliese G, Grazi GL, Perri P, et al. A bioluminescent mouse model of proliferation to highlight early stages of pancreatic cancer: a suitable tool for preclinical studies. Ann Anat. 2016;207:2-8.

30. Negrisoli G, Canevotti R, Previtali M, Aldini G, Carini M, Orioli M, et al. Amino alcohol derivatives and their therapeutic activitiesPatent application No: WO/2011/080139; International Application No.: PCT/EP2010/070238; https:// patents.google.com/patent/WO2011080139A1/fi; 2011.

31. Menini S, lacobini C, Ricci C, Blasetti Fantauzzi C, Salvi L, Pesce CM, et al. The galectin-3/RAGE dyad modulates vascular osteogenesis in atherosclerosis. Cardiovasc Res. 2013;100:472-80.

32. Hao Y, Chun A, Cheung K, Rashidi B, Yang X. Tumor suppressor LATS1 is a negative regulator of oncogene YAP. J Biol Chem. 2008;283:5496-509.

33. Rozengurt E, Sinnett-Smith J, Eibl G. Yes-associated protein (YAP) in pancreatic cancer: at the epicenter of a targetable signaling network associated with patient survival. Signal Transduct Target Ther. 2018;3:11.

34. Zhao B, Ye X, Yu J, Li L, Li W, Li S, et al. TEAD mediates YAP-dependent gene induction and growth control. Genes Dev. 2008;22:1962-71.

35. King AJF. The use of animal models in diabetes research. Br J Pharmacol. 2012;166:877-94.

36. Chiavarina B, Nokin MJ, Durieux F, Bianchi E, Turtoi A, Peulen O, et al. Triple negative tumors accumulate significantly less methylglyoxal specific adducts than other human breast cancer subtypes. Oncotarget. 2014;5:5472-82.

37. Moroishi T, Hansen CG, Guan KL. The emerging roles of YAP and TAZ in cancer. Nat Rev Cancer. 2015;15:73-9.

38. Mo JS, Meng Z, Kim YC, Park HW, Hansen CG, Kim S, et al. Cellular energy stress induces AMPK-mediated regulation of YAP and the hippo pathway. Nat Cell Biol. 2015;17:500-10.

39. Maeta M, Izawa S, Okazaki S, Kuge S, Inoue Y. Activity of the Yap1 transcription factor in Saccharomyces cerevisiae is modulated by methylglyoxal, a metabolite derived from glycolysis. Mol Cell Biol. 2004;24: 8753-64.

40. Martins AM, Cordeiro CA, Ponces Freire AM. In situ analysis of methylglyoxal metabolism in Saccharomyces cerevisiae. FEBS Lett. 2001;499:41-4.

41. Maessen DE, Stehouwer CD, Schalkwijk CG. The role of methylglyoxal and the glyoxalase system in diabetes and other age-related diseases. Clin Sci (Lond). 2015;128:839-61.

42. Han Y, Randell E, Vasdev S, Gill V, Curran M, Newhook LA, et al. Plasma advanced glycation endproduct, methylglyoxal-derived hydroimidazolone is elevated in young, complication- free patients with type 1 diabetes. Clin Biochem. 2009;42:562-9.

43. Nakayama K, Nakayama M, Iwabuchi M, Terawaki H, Sato T, Kohno M, et al. Plasma alpha-oxoaldehyde levels in diabetic and nondiabetic chronic kidney disease patients. Am J Nephrol. 2008;28:871-8.
44. Chen SC, Guh JY, Hwang CC, Chiou SJ, Lin TD, Ko YM, et al. Advanced glycation end-products activate extracellular signal-regulated kinase via the oxidative stress-EGF receptor pathway in renal fibroblasts. J Cell Biochem. 2010;109:38-48.

45. Cai W, He JC, Zhu L, Lu C, Vlassara H. Advanced glycation end product (AGE) receptor 1 suppresses cell oxidant stress and activation signaling via EGF receptor. Proc Natl Acad Sci U S A. 2006;103:13801-6.

46. Wagner M, Weber CK, Bressau F, Greten FR, Stagge V, Ebert M, et al. Transgenic overexpression of amphiregulin induces a mitogenic response selectively in pancreatic duct cells. Gastroenterology. 2002;122:1898-912.

47. Navas C, Hernández-Porras I, Schuhmacher AJ, Sibilia M, Guerra C, Barbacid M. EGF receptor signaling is essential for k-ras oncogene-driven pancreatic ductal adenocarcinoma. Cancer Cell. 2012;22:318-30.

48. Engle DD, Tiriac H, Rivera KD, Pommier A, Whalen S, Oni TE, et al. The glycan CA19-9 promotes pancreatitis and pancreatic cancer in mice. Science. 2019;364:1156-62.

49. Blasco MT, Navas C, Martín-Serrano G, Graña-Castro O, Lechuga CG, MartínDíaz $\mathrm{L}$, et al. Complete regression of advanced pancreatic ductal adenocarcinomas upon combined inhibition of EGFR and C-RAF. Cancer Cell. 2019;35:573-87.

\section{Publisher's Note}

Springer Nature remains neutral with regard to jurisdictional claims in published maps and institutional affiliations.
Ready to submit your research? Choose BMC and benefit from:

- fast, convenient online submission

- thorough peer review by experienced researchers in your field

- rapid publication on acceptance

- support for research data, including large and complex data types

- gold Open Access which fosters wider collaboration and increased citations

- maximum visibility for your research: over $100 \mathrm{M}$ website views per year

At BMC, research is always in progress.

Learn more biomedcentral.com/submissions 